\title{
A pedagogia da alternância e a cidade: os desafios da escola família agrícola "São Bento do Chapéu" diante da matrícula de estudantes residentes do meio urbano
}

The pedagogy of alternation and the city: the challenges of the agricultural family school "São Bento do Chapéu" before the enrollment of students residing in the urban environment

Samuel Pinheiro da Silva Santos Flaviane Geraldo Patricia Hand Littig Wellington Raach

Resumo: A temática que subsidia este estudo busca entender o que move os alunos do perímetro urbano de Domingos Martins e Marechal Floriano a se matricularem na Escola Família Agrícola (EFA) São Bento do Chapéu, visto que o contexto rural se contrapõe a realidade desses estudantes. Também se propõe compreender os desafios de ensino e aprendizagem diante desse novo contexto escolar nesta escola, que adota a Pedagogia da Alternância. A investigação se norteia a partir de uma pesquisa qualitativa com docentes e discentes que atuam na EFA São Bento do Chapéu. Como instrumento de coleta de dados, utilizamos um questionário com questões sobre o que motiva os alunos do meio urbano a se matricular na EFA e os desafios ali encontrados. Os resultados do estudo remetem a singularidade de se cultivar saberes necessários à Pedagogia da Alternância e de enfrentamento de novos desafios teóricos e práticos da escola.

Palavras-chave: Educação do Campo. Pedagogia da Alternância. Escola Família Agrícola. Campo. Cidade.

Abstract: The theme that supports this study seeks to understand what moves students from the urban perimeter of Domingos Martins and Marechal Floriano to enroll in the Escola Família Agrícola (EFA) São Bento do Chapéu, since the rural context is opposed to the reality of these students. It is also proposed to understand the challenges of teaching and learning in the face of this new school context in this school, which adopts Pedagogy of Alternation. The investigation is guided by a qualitative research with teachers and students who work at EFA São Bento do Chapéu. As a data collection instrument, we used a questionnaire with questions about what motivates urban students to enroll in EFA and the challenges encountered there. The results of the study refer to the singularity of cultivating the knowledge necessary for Pedagogy of Alternation and facing new theoretical and practical challenges of the school.

Keywords: Rural Education. Pedagogy of Alternation. Agricultural Family School. Field. City. 


\section{Introdução}

A Escola Família Agrícola (EFA) "São Bento do Chapéu", ensino fundamental, séries finais, surgiu em 1992 da iniciativa de camponeses e camponesas preocupados com a continuidade dos estudos de seus filhos. Optaram pela Pedagogia da Alternância a fim de valorizar as raízes campesinas visando um currículo do campo para o campo.

Ao longo dos anos de funcionamento da EFA "São Bento do Chapéu", foi priorizada a formação de sujeitos do Campo com o intuito de provocar o sentimento de pertença à terra. Essa preocupação se deu devido ao fluxo de muitas pessoas do campo para áreas urbanas, o que acarretou o esvaziamento contínuo do meio rural. Nesse sentido, tornou-se primordial educar para o campo. Porém, nos últimos anos, tem se notado uma quantidade expressiva de matriculas de estudantes oriundos do meio urbano na EFA "São Bento do Chapéu". Como este fator impacta, tanto a vida do educando como da escola, se torna relevante pensar nos motivos que levam esses sujeitos a se matricularem na referida unidade de ensino e, por conseguinte, entender as práticas pedagógicas desenvolvidas a partir dessa nova realidade.

Essa escola tem uma parceria com o MEPES (Movimento de Educação Promocional do Espírito Santo). O referido “Centro de Formação e Reflexão" traz em sua trajetória uma vasta experiência de intercâmbio e formação de pessoas para atuarem em diferentes instituições que se preocupam com sujeitos do campo e com a educação popular. Por meio dessa parceria, a escola se fortaleceu e conseguiu ampliar o atendimento a um número maior de comunidades e pessoas da cidade. Como se trata de uma escola agrícola, é priorizada questões da realidade campesina.

Além da constatação de matrículas de alunos residentes no meio urbano, o que nos motivou realizar tal pesquisa é saber que, na atualidade, principalmente nas cidades, existe uma busca, de algumas pessoas, a formas de educação que supere a simples transmissão alienante de conteúdo.

Segundo Dufour (2005) ocorre na sociedade atual a dessimbolização do mundo, ou seja, a diluição de valores provocada pelas relações sociais baseadas na lógica de mercado. Isso gera um fenômeno social definido como servidão 
voluntária (DUFOUR, 2005). Partindo desse ponto de vista, existem relações sociais de dominação superficiais e exploratórias. Dessa forma, a relação com o mundo se fragiliza. Devido à concretização desses fatores, muitas pessoas no mundo buscam modos de vida e formação alternativas. A vida e a formação no campo aparecem como uma dessas possibilidades para sair de um universo alienante e alcançar um senso crítico no mundo cada vez mais capitalista.

A construção do saber junto aos educandos é uma das características das EFA's, pois consideram que ensinar e aprender acontece de forma dialógica e contínua. Sendo assim, não cabe a escola delimitar o espaço, rural ou urbano, que o sujeito deverá ocupar após sua formação, mas educa-lo para que possa fazer suas escolhas de modo consciente. Ativamente nesse processo, está a proposta da escola e, principalmente, dos educadores e educadoras que devem contribuir para a formação de sujeitos autônomos. Segundo o pensamento freiriano:

O professor..., deixa transparecer aos educandos que uma das bonitezas de nossa maneira de estar no mundo e com o mundo, como seres históricos, é a capacidade de, intervindo no mundo, conhecer o mundo. Mas, histórico como nós, o nosso conhecimento do mundo tem historicidade (FREIRE, 2014, p. 30).

Essa capacidade do ser humano como seres históricos é explicitada por Freire (2014, p. 31) da seguinte forma:

Em termos críticos, é uma exigência que os momentos do ciclo gnosiológico vão pondo à curiosidade que, tornando-se mais e mais metodicamente rigorosa, transita da ingenuidade para o que venho chamando "curiosidade epistemológica".

Sabendo da importância de se formar sujeitos críticos e autônomos é que decidimos analisar como as práticas educativas da EFA "São Bento do Chapéu" são desenvolvidas com os alunos advindos do espaço urbano. Para isso, delimitamos um objetivo geral desse estudo, que pode ser compreendido a partir da seguinte pergunta: Quais os motivos que tem levado estudantes, residentes no perímetro urbano, a se matricularem na EFA São Bento do Chapéu? Essa pergunta nos levou a um objetivo geral e específicos da pesquisa.

Objetivo Geral: 
Compreender os motivos que tem levado estudantes, residentes no perímetro urbano, a se matricularem na EFA São Bento d Chapéu.

Objetivos específicos:

Realizar um levantamento dos alunos residentes no perímetro urbano de Domingos Martins com matrícula na EFA.

Dialogar com alunos residentes no perímetro urbano e matriculados na EFA, bem como com os professores para entender quais as ações pedagógicas desenvolvidas pela escola que despertam a busca dos alunos pela instituição.

Entender como o trabalho pedagógico é avaliado por alunos e professores e as implicações desse processo na escola pela matrícula de alunos residentes no perímetro urbano na unidade de ensino.

Para realizarmos esse trabalho de pesquisa, dialogamos com autores que analisam a vida em sociedade e primordialmente como se dão os processos de ensino-aprendizagem relacionados a práticas educativas adotadas numa escola do campo. Pode-se observar na obra "A arte de reduzir as cabeças" (DUFOUR, 2005), o quanto opressor e alienante um sistema pode ser, utilizando diversas práticas e meios para promover a servidão dos sujeitos. Uma das formas de romper com essa estrutura alienante é posta por Freire (2014) como sendo a formação de sujeitos críticos através de práticas mediadas por educadores e educadoras de cunho transformador e crítico.

Além disso, é importante compreender como questões sociais impactam a vida das pessoas. Por isso a importância de valorizar a coletividade e a singularidade, que podem definir o processo de ensino-aprendizagem de uma escola. Contudo, se faz necessário entender, significar e re-significar as práticas educativas na busca pela formação de sujeitos críticos e autônomos (LIBÂNEO, 2001).

\section{Metodologia}

Visando compreender os motivos que levam os estudantes do meio urbano a procurarem pela matrícula na EFA São Bento do Chapéu, localizada em área rural do município de Domingos Martins, foi adotado a pesquisa qualitativa como metodologia para tal exploração. Segundo Deslandes (2009), 
Quando tratamos da pesquisa qualitativa, frequentemente as atividades que compõem a fase exploratória, além de antecederem à construção do projeto, também a sucedem. Muitas vezes, por exemplo, é necessário uma aproximação maior com o campo de observação para melhor delinearmos outras questões, tais como os instrumentos de investigação e o grupo de pesquisa. Tendo uma visão mais ampla, podemos dizer que a construção do projeto é, inclusive, uma etapa da fase exploratória.

Entendemos que tal pesquisa corrobora para o entendimento de questões humanas e sociais. Para trabalhar o tema em questão foram elencados os sujeitos da pesquisa. Trata-se de 5 estudantes urbanos que possuem vínculo com a EFA São Bento do Chapéu. Estes são identificados com nomes fictícios de: Yuri aluno do $9^{\circ}$ ano do Ensino Fundamental, do gênero masculino, 16 anos; Ítalo é do gênero masculino e está com 15 anos; Brenda é do gênero feminino e tem 13 anos; Joaquim do gênero masculino e possui 14 anos; e Elvis é um aluno com 12 anos de idade. Ítalo, Brenda, Joaquim e Elvis estão cursando o $7^{\circ}$ ano do Ensino Fundamental.

Além dos educandos, envolvemos os educadores e educadoras da Escola, no qual são 5 profissionais, também identificados com nomes fictícios: Vanuza é diretora e tem 39 anos de idade, possui Licenciatura Plena em Letras e pós-graduação em Educação do Campo e Educação Inclusiva e Linguagens, e ainda 21 anos de atuação na escola. Denise professora formada em Bacharel em Zootecnia e Licenciatura em Matemática e pós-graduada em Inclusão e Diversidade e EJA, possui 34 anos e atua a 8 anos na EFA. Dyogo é professor licenciado em Geografia e cursando pós-graduação em Educação Inclusiva e Diversidade. Tem 22 anos de idade e atua a 4 anos e 6 meses na escola. A professora Sara formada em Bacharel em Jornalismo e Licenciatura em Pedagogia, cursando pós-graduação em Educação Inclusiva e Diversidade, possui 24 anos de idade e atua a 3 meses na escola. E o professor e coordenador pedagógico Cleiton licenciado em Ciências Biológicas e pósgraduado em Ciências Biológicas, Educação Especial e Inclusiva e Educação do Campo, possui 39 anos de idade e 16 anos de atuação na EFA. 
Para a realização do estudo, foi apresentado à direção da escola a pesquisa e ressaltado os objetivos do estudo. Após o consentimento da direção, foi agendada a apresentação do trabalho para a equipe escolar na reunião semanal. Cientes do trabalho e autorizado a pesquisa, foi apresentado o questionário como instrumento de coleta de dados aos professores e realizado um levantamento dos alunos que residem em área urbana com matrícula na Escola Família Agrícola.

Em seguida, apresentamos a pesquisa para os(as) alunos(as) e para os professores(as) e solicitamos a assinatura, pela família, do Termo de Consentimento Livre e Esclarecido no período de alternância em casa, bem como para os docentes envolvidos. Após o retorno à escola, foi devolvido o termo pelos alunos e apresentado o questionário aos mesmos individualmente. Esses foram respondidos em horários vagos dos alunos. Já os educadores, responderam o questionário na sala dos professores em momento de planejamento, utilizando 30 minutos.

Feito a coleta de dados, no período de abril e maio de 2016, foi preservado a identificação dos sujeitos envolvidos e as informações coletadas dialogaram com as contribuições de Freire (2014) e com a literatura pertinente à Educação do Campo. Esta pesquisa reflete, então, a realidade da EFA São Bento do Chapéu no decorrer do ano letivo de 2016. Neste ano nós, autores deste artigo, estávamos cursando a Graduação de Licenciatura em Educação do Campo na Universidade Federal do Espírito Santo (UFES).

\section{Dimensões do ensino e aprendizagem na escola família agrícola São Bento Do Chapéu: Novos sujeitos, novos desafios}

A Pedagogia da Alternância é adotada atualmente em muitas EFA's e Centros Familiares de Formação por Alternância (CEFFA's), que optaram por essa prática pedagógica pelas necessidades de comunidades camponesas ao longo dos anos. Essa prática de ensino foi trazida da França e atualmente é bastante difundida no Brasil. No estado do Espírito Santo existem EFA's e/ou CEFFA's de norte a sul do estado capixaba, conveniadas ao MEPES e a Regional das Associações dos Centros Familiares de Formação em Alternância 
do Espírito Santo (RACEFFAES). Essas instituições, além de viabilizarem o ensino em comunidades camponesas, também fortalecem a Educação do Campo, junto aos movimentos sociais.

Diante da importância histórica dessas instituições, nos propusemos a problemática aqui situada, de uma EFA de Domingos Martins. A pesquisa teve como norteadores dois modelos de questionários: um aplicado para os professores e outro para alunos residentes no meio urbano, mas que se encontram matriculados em escola do campo. Ambos com vínculo na Escola Família Agrícola EFA "São Bento do Chapéu". Como a preocupação é compreender os motivos que levam os estudantes residentes no perímetro urbano a procurarem pela matrícula na EFA, localizada em área rural do município, começamos com a experiência trazida pelos professores sobre 0 assunto. Notamos que, em relação á matrícula destes educandos, uma professora afirma que "[...] a necessidade de uma experiência no meio rural" é o fator crucial para a procura e vinculação desses estudantes (SARA).

Em relação ao mesmo questionamento, outra professora pontuou alguns outros fatores que merecem ser analisados e também concebidos como primordiais para a compreensão do processo de ensino-aprendizagem da escola. A educadora aponta questões relacionadas à aprendizagem, à família e à convivência em grupo. "[...] muitos são os motivos, dentre eles: dificuldades de aprendizagem; falta de limites/ regras estabelecidas pela família; possibilitar a convivência em grupo" (VANUSA).

Outros dois motivos também são apontados pelo professor e também coordenador pedagógico, sendo que o primeiro seria: [...] "as atividades pedagógicas realizadas na escola, a convivência em tempo maior com colegas e professores" (CLEITON). Já o segundo motivo seria:

Pela imposição dos pais, que não suportam mais serem convidados constantemente na escola de ensino regular e buscam uma nova possibilidade e oportunidade de educação para seus filhos. Ou dividirem as indisciplinas dos filhos com a escola - uma semana em casa e outra na escola (CLEITON).

Dessa forma, nota-se a relação da escola com a realidade dos(as) alunos(as). Também é possível observar que a responsabilidade pelo estudante, para além da escolarização, é 
transferida pela família para a escola. Essa dinâmica estabelecida entre família e escola é descrita também por outros dois educadores, que destacam a Pedagogia da Alternância como elemento motivador da matrícula.

Infelizmente na maioria das vezes o que leva esses alunos se matricularem na Escola é o fato da família não ter tempo para se dedicar ao filho, sendo a criança indisciplinada ou repetente em outras escolas (DENISE).

Muitas vezes percebo que esses alunos são matriculados não por vontade própria, mas sim por vontade da família, na busca de uma mudança promovida pela P.A. (DYOGO).

$\mathrm{Na}$ constatação da educadora e do educador, a EFA é procurada por algumas famílias para solucionar problemas educacionais de filhos e filhas. Com estes novos desafios, a Pedagogia da Alternância (PA) objetiva um processo educativo primordial para a relação entre escola e comunidade ou famílias de diversas comunidades e espaços urbanos.

Uma das complexidades da Alternância está na diversidade de relações: com pessoas que colaboram com o processo da formação, com entidades parceiras, com espaços de tempos diferentes (tempo-escola e tempo comunidade), com as diversidades culturais do campo, com os diversos campos dos saberes: práticos, populares, empíricos e teórico-científicos, entre outros. Isto faz da alternância uma pedagogia dialógica ou uma pedagogia do encontro (BEGNAMI, 2006, p.33).

Esse tipo de proposta pedagógica traz para os educadores uma série de desafios, quando se trata de educandos vinculados a EFA, mas que moram no meio urbano. Assim, outros métodos para a execução das atividades voltadas para o campo são pensados para atender às possibilidades dos(as) estudantes. Isso não muda a proposta, nem a intenção da PA, pois ela norteia todo o processo educativo da escola. Tendo em vista a formação dos alunos, as concepções das professoras e professores foram diversas. Para Vanuza, Sara e Claudio, a Pedagogia da Alternância e a experiência no campo é, respectivamente, necessária para essa formação.

A formação que os alunos recebem na EFA é integral, ou seja, a Pedagogia da Alternância possibilita uma dinâmica educativa voltada para o homem do campo que tem, entre os seus pilares, o desenvolvimento do meio e a formação integral do educando (VANUZA). 
Os alunos que aqui estudam recebem um estudo de qualidade, além da prática no meio (do campo) como experiência (SARA).

Avalio como excelente, pois, através da Pedagogia da Alternância e de suas ferramentas pedagógicas o aluno tem a oportunidade de se desenvolver criticamente enquanto ser humano, se posicionar diante de determinados eventos $\mathrm{e}$ argumentar defendendo seu ponto de vista (CLEITON).

Considerar a experiência do educando é algo primordial em uma escola, porque constrói práticas educativas efetivas e por meio do diálogo contribui para a reconstrução de novas práticas. Dessa forma, pode-se afirmar que: "[...] a educação é, assim, uma prática humana, uma prática social, que modifica os seres humanos nos seus estados físicos, mentais, espirituais, culturais, que dá uma configuração à nossa existência humana individual e grupal" (LIBÂNEO, 2001, p. 7).

Todavia, se torna importante, na visão dos professores Denise, Dyogo e Claudio, a formação dos estudantes para a vida, sem descartar um aprendizado de cunho científico.

A EFA não forma somente os alunos para os conteúdos, mas para a vida, tendo o mesmo uma consciência crítica para viver em sociedade (DENISE).

Uma formação para a vida, que vai muito além de uma sala de aula. Aprendendo na prática e na convivência valores que complementam um profissional flexível, sem deixar de ensinar os conteúdos regulares (DYOGO).

É essencial entender e praticar a formação crítica dos alunos, pois é dessa forma que os sujeitos conseguem romper com as opressões presentes na sociedade. Independentemente do espaço habitado pelo aluno, campo ou cidade, é necessária a busca pela interação com o mundo, explorando a criticidade com propulsor da convivência e do dialogo. Sobre a formação do sujeito crítico Freire (2014) argumenta que:

Não há para mim, na diferença e na distancia entre a ingenuidade e criticidade, entre o saber de pura experiência feito e o que ressalta dos procedimentos metodicamente rigorosos, uma ruptura, mas uma superação. A superação e não a ruptura se dá na medida em que a curiosidade ingênua, sem deixar de 
ser curiosidade, pelo contrário, continuando a ser curiosidade, se criticiza (p. 32).

Ainda é comum encontrar instituições que sugerem abordagem crítica, mas, na prática, não conseguem democratizar o processo educativo, apostam num ensino embasado na transmissão do conhecimento. Freire (1987) critica esse modelo de educação, definindo-o como Educação Bancária. É possível, muitas vezes, perceber como "[...] os sistemas de avaliação pedagógica de alunos e de professores vêm se assumindo cada vez mais como discursos verticais, de cima para baixo, mas insistindo em passar por democráticos" (FREIRE, 2014, p. 113).

$\mathrm{Na}$ contramão de uma educação bancária, é necessário frisar a importância da formação de um sujeito crítico e de profissionais com olhar emancipatório. Assim, se faz necessário entender o trabalho pedagógico e suas dimensões no âmbito escolar, sobretudo, saber como os educadores da EFA desenvolvem planejamentos para atingir o objetivo de ensinar. Sob o olhar dos professores, o trabalho deve ser pautado na realidade dos(as) alunos(as), relacionando o saber cientifico e social, embasado na PA.

O trabalho pedagógico também é baseado em inúmeras ferramentas pedagógicas da pedagogia da Alternância (VANUZA).

Tais ferramentas são apontadas por como o plano de estudo, atividade de retorno, estágios, projetos, entre outros (DENISE).

Para educandos do meio urbano, é feito um acordo de compromisso com a família para garantir / possibilitar a execução dessas ferramentas pedagógicas (VANUZA).

O trabalho pedagógico da EFA é organizado através de temas geradores trimestrais, em que os conhecimentos são planejados, organizados e trabalhados em cada ano (série). $\mathrm{O}$ temas geradores fazem parte da realidade dos alunos, por isso, as pesquisas são desenvolvidas primeiro com a família e a partir dos conhecimentos que vem do cotidiano dos alunos são trabalhados os conhecimentos científicos que fazem parte da proposta curricular da EFA (CLEITON).

Percebe-se no trabalho pedagógico elaborado pela EFA o quanto a escola está vinculada às comunidades campesinas pelo fato de ser voltado para o sujeito no campo e do campo. Quando a educação é ofertada para alunos que 
vêm do meio urbano, é possível perceber os desafios, que a escola ainda encontra, porque, apesar da distancia e realidade distinta, eles têm que se adequar a realidade da escola.

O trabalho com estes estudantes acontece na perspectiva de formação de um sujeito crítico, mas para alcançar esse objetivo outras ferramentas e mecanismos são utilizados. Roda de conversa, acompanhamento das atividades retorno, diálogo permanente com a família e abordagem crítica do conteúdo tem sido os caminhos para alcançar tais objetivos. Com a preocupação em saber o que os educadores apontam para a melhoria do processo de ensinoaprendizagem dos alunos advindos do meio urbano é que tal questionamento foi a eles apresentado. A intenção é compreender as situações limites (FREIRE, 2014) enfrentadas pela escola em diversos aspectos, principalmente, no que se refere ao processo de ensino-aprendizagem.

Nesse sentido, Dyogo afirma: "[...] espero apenas que possamos prosseguir firmes no trabalho, fortalecendo sempre a PA". Com o interesse em re-sinificar o saber científico, a professora Sara sugere a seguinte alternativa: "[...] acredito que poderíamos ter mais aulas práticas, não só nas propriedades, mas também em laboratórios de informática, tendo mais acesso. Seria legal termos um laboratório de ciências". Para Denise, a Pedagogia da Alternância deveria ser mais reconhecida. Ela afirma que "[...] o que falta para melhoria do ensino é uma melhor infraestrutura e o reconhecimento dos órgãos públicos para a importância desse projeto". Já Vanuza acredita que deve "[...] manter as atividades pedagógicas, priorizando-as; buscar sempre parcerias a nível de formação, cursos, palestras, bem como recrutar recursos financeiros, projetos e envolver sempre as famílias e comunidades nesse projeto". No entender do professor e coordenador pedagógico Clédio,

Seria necessário repensar as políticas públicas que valorizem mais a educação do/no campo de fato em sua realização na integra na prática. Por exemplo: para a realização de atividades práticas relacionadas aos temas geradores desenvolvidos, as vezes são impossibilitadas de realizar por falta de transporte ou outros recursos.

Tendo em vista os apontamentos feitos pelos educadores, pode-se afirmar que a educação se faz e se refaz num processo dialógico entre os 
sujeitos, tendo em vista a formação de um sujeito mais humano, em consonância com a proposta da Educação do Campo, sobretudo afirmam a importância da Pedagogia da Alternância. Segundo Freire (2014) a formação dos sujeitos está relacionada as diversas oportunidades de acesso a cultura, situação que o faz afirmar que:

Gosto de gente porque, mesmo sabendo que as condições materiais, econômicas, sociais e políticas, culturais e ideológicas em que nos achamos geram quase sempre barreiras de difícil superação para o cumprimento de nossa tarefa histórica de mudar o mundo, sei também que os obstáculos não se eternizam (p. 53).

Além disso, depende de políticas públicas voltadas para as escolas do campo. Essa luta por meio de políticas públicas é uma marca da mobilização realizada ao longo dos anos por educadores e movimentos sociais, por uma Educação do Campo. A nossa luta é no campo das políticas públicas, porque esta é a única maneira de universalizarmos o acesso de todo o povo a educação (CALDART, 2002, p. 18-19).

Além dos professores, tivemos os(as) alunos(as) inseridos(as) na pesquisa. Elaboramos questionários para eles(as) responderem. Primeiramente, perguntamos como os(as) alunos(as) passaram a saber da existência da EFA São Bento do Chapéu. Em geral, as respostas destacam ser por meio de professores, conhecidos e pela própria família. Percebemos que as pessoas que já tiveram experiências positivas e que acreditam no trabalho da escola, divulgaram e incentivaram a matrícula desses alunos na unidade de ensino.

Outra questão que merece destaque são os motivos que levaram os alunos a se matricularem na EFA. Para os respondentes, a questão é justificada pelas características da Pedagogia da Alternância (PA) adotada pela Escola, pela qualidade de ensino e pelo anseio por novas experiências . Segundo esses sujeitos:

O interesse de viver uma nova experiência (BRENDA).

Os motivos são que aqui na EFA tinha que trabalhar na roça e que tinha que ficar uma semana na escola (JOAQUIM).

Por gostar da Pedagogia da Alternância (YURI). 
...pela curiosidade de saber como era essa escola, e que eu gosto muito da área rural (ELVIS).

Por que precisava melhorar em questão de estudo (ÍTALO).

De acordo com as respostas, as características da Pedagogia da Alternância, entre outras coisas, é que atrai estudantes do perímetro urbano a se aventurarem em uma realidade pedagógica diferente. A Alternância entre a Escola e a Família, permite um convívio mais intenso com colegas, monitores (professores) e demais profissinais, facilitando um ambiente favorável para o processo de ensino-aprendizagem. O distanciamento de suas realidades aparentes permite ampliar a percepção de ensino, refletir e tomar consciência sobre o mundo. Freire (2014) reforça essa ideia dizendo que:

O seu 'distanciamento' epistemológico da prática enquanto objeto de sua análise, deve dela 'aproxima-lo' ao máximo. Quanto melhor faça esta operação tanto mais inteligência ganha da prática em análise e maior comunicabilidade exerce em torno da superação da ingenuidade pela rigorosidade (p. 40).

Destacamos como princípios da PA: um currículo que parte da realidade e valoriza a cultura do estudante e sua comunidade; um conjunto de atividades informais complementares que estimulam a criatividade e autonomia; a manutenção dos vínculos do jovem com sua família e comunidade; o rompimento com preconceitos contra o meio rural e os povos camponeses. Enfim, a Alternância oferece condições de valorização da vida e priorização das experiências como meio de aprendizagem e lugar de intervenções.

Os alunos ainda avaliaram a formação que recebem na EFA. Três respondentes destacaram a forma de ensinar que se diferencia das demais escolas que frequentaram, afirmando que:

Pra mim a EFA tem um ensino muito diferente de outras escolas, é muito bom aqui você aprende rápido (JOAQUIM).

O estudo que eu recebo na EFA é muito bom porque o jeito de ensinar é excelente (ITALO).

Muito bom, pois os professores são legais e eu aprendo muito (ELVIS). 
Os argumentos evidenciam que a Pedagogia da Alternância tem se mostrado como um sistema ativo, dinâmico, inacabado e que não se limita aos seus antecedentes históricos, mas se constrói num processo de crescimento contínuo em que o projeto educativo caminha na base de um movimento participativo, envolvendo famílias, comunidades, entidades e profissionais. Assim, o(a) aluno(a) e sua realidade englobam a centralidade do projeto educativo. Freire (2014) complementa:

[...] nas condições de verdadeira aprendizagem os educandos vão se transformando em reais sujeitos da construção e da reconstrução do saber ensinando, ao lado do educador, igualmente sujeito do processo. Só assim podemos falar realmente de saber ensinando, em que o objeto ensinado é aprendido na sua razão de ser e, portanto, aprendido pelos educandos (p.28).

Nesse sentido, a Pedagogia da Alternância busca romper com o ensino baseado na transmissão vertical dos conhecimentos e educação bancária. 0 conhecimento se constrói na interação das pessoas entre si e das pessoas com o meio em que estão inseridas.

Dois alunos avaliam a formação de forma positiva, justificando a importância do que é ensinado. Segundo eles:

A formação que recebo é boa por que eu gosto do que eles passam aqui (YURI).

Excelente. Aqui o aprendizado é muito bom, além de aprendermos algumas coisas do campo, aprendemos a fazer algumas tarefas de casa que iremos fazer futuramente (BRENDA).

Na Pedagogia da Alternância, o Plano de Formação da Escola contém tema de "planos de estudos" baseados na realidade e conteúdos curriculares formais do ensino da Base Nacional Comum Curricular (BNCC) e da Educação Profissional trabalhados a partir dos temas da realidade e de forma interdisciplinar. Assim como o tema do plano de estudo busca dar unidade entre as alternâncias, o Plano de Formação tenta dar unidade ao curso como um todo por meio de uma sequência progressiva de temas, além de tentar integrar os diversos conteúdos disciplinares e trabalha-los em função dos temas da realidade. Segundo Gimonet (2007), é importante 
Criar uma escola que não mantenha os adolescentes presos entre quatro paredes, mas que lhes permita aprender através dos ensinamentos da escola, com certeza, mas também através daqueles da vida quotidiana, graças a uma alternância de períodos entre ambiente familiar e o centro escola (p. 22).

Afirmando a necessidade de valorizar os saberes que adentram o espaço escolar, Freire (2014) afirma que cabe

[...] ao professor ou, mas amplamente, à escola, o dever de não só respeitar os saberes com que os educandos, sobretudo o das classes populares, chegam a ela saberes socialmente construídos na prática comunitária - mas também, como a mais de trinta anos venho sugerindo, discutir com os alunos a razão de ser de alguns desses saberes em relação com o ensino dos conteúdos (p. 31).

Daí a importância do trabalho com Temas Geradores e dos Planos de Estudo, objetivando valorizar a bagagem de conhecimento dos alunos, mediando a construção de um novo conhecimento.

Os alunos também foram indagados sobre que mais gostam na escola. Três alunos ressaltaram que o momento de por em prática os estudos realizados em sala lhes agradam muito.

Os trabalhos práticos porque com a prática aprendem melhor (YURI).

A aula prática, porque ela é uma hora livre para ajudar na propriedade da escola (ELVIS).

Trabalhar na roça, porque você aprende a capinar e plantar e colher (JOAQUIM).

As afirmativas acima apresentadas reforçam a ideia de que a melhor forma de aprender é pelo fazer. Nesse sentido, a Alternância prioriza a experiência, valoriza a vida e dá um sentido aos saberes que se busca construir, ou seja, o processo de aprendizagem opera a partir da realidade observada e refletida, do mesmo modo que retorna com compromisso de intervir e de buscar soluções para os problemas que a realidade apresenta. Segundo Freire (2014),

Este é outro saber indispensável à prática docente. O saber da impossibilidade de desunir o ensino dos conteúdos da formação ética dos educandos. De separar prática de teoria, autoridade de liberdade, ignorância de saber, respeito ao professor de respeito 
aos alunos, ensinar de aprender. Nenhum destes termos pode ser mecanicistamente separado, um do outro (p. 93).

Outros dois alunos afirmaram que a relação entre professor e aluno, em especial, é algo que desperta o interesse em estudar na escola. Assim destacam:

O contato que tenho com os professores porque tenho uma relação com os professores, converso com eles dentro e fora de sala de aula (ÍTALO).

A forma que nos tratam e os estudos, todos aqui são muito carinhosos e competentes, nos ensinam muitas coisas (BRENDA).

Percebemos que essa relação intensa entre professor e aluno é favorecida pela semana em que ficam na escola, ou seja, o Tempo Escola (TE), que oferece condições psicológicas e afetivas permitindo um clima facilitador de convivência e de aprendizagens com qualidade de vida. Além disso, na PA o professor, além de formador, deve ser um agente social comprometido com uma lógica de formação e de promoção das pessoas e do meio onde elas vivem. Nas palavras de Freire (2014),

Como prática estritamente humana jamais pude entender a educação como uma experiência fria, sem alma, em que os sentimentos e as emoções, os desejos, os sonhos devessem ser reprimidos por uma espécie de ditadura reacionalista (p. 142).

Na questão sobre as sugestões, os alunos alegaram não ter sugestão já que foram bem acolhidos pela escola. Diante disso, avaliam de forma positiva o fato de estarem matriculados na EFA São Bento do Chapéu.

Eu queria que a escola fosse interna, pois ela é muito legal (ELVIS).

Não acho que deveria haver nenhuma melhoria pois a escola é excelente (BRENDA).

Nenhuma por que a escola já está boa (ÍTALO).

Não tenho nada a reclamar, só agradecer pelo ensino que a EFA trás para a gente... (JOAQUIM).

Não precisa melhorar nada, está bom assim (YURI).

Essas falas confirmam a satisfação dos alunos em estudar numa Escola do Campo, que adota a Pedagogia da Alternância. Sentir que estão sendo 
inseridos amplia a possibilidade de se relacionarem com a forma de ensino ali desenvolvida e também com o mundo. Freire (2014) defende que:

O fato de me perceber no mundo, com o mundo e com os outros me põe numa posição em face do mundo que não é de quem nada tem a haver com ele. Afinal, minha presença no mundo não é a de quem a ele se adapta, mas de quem nele se insere ( $p$. 53).

Analisando os motivos que levam os estudantes residentes no perímetro urbano de Domingos Martins e Marechal Floriano a procurarem pela matrícula na Escola Família Agrícola, pudemos perceber que independente de sua origem, comunidade e perspectiva, a Escola acolhe a todos, oferecendo condições ao educando de escolher seu próprio caminho enquanto cidadão, seja no campo ou na cidade. Sem abrir mão dos instrumentos pedagógicos da Pedagogia da Alternância, os educadores introduzem os estudantes na proposta principalmente por meio do diálogo. Esta relação com a escola somado as atividades práticas atrai e motiva esses novos estudantes.

\section{Considerações}

Consideramos que são vários os motivos que levam os alunos de perímetros urbanos a se matricularem na EFA. A matrícula desses alunos desencadeia todo um trabalho por parte dos profissionais para adaptação desses sujeitos à escola, assim, outros métodos para a execução das atividades voltadas para o campo são pensados, visando a atender às possibilidades/necessidades do estudante. Isso não muda a proposta, nem a intenção da Pedagogia da Alternnância, pois ela norteia todo o processo educativo da escola.

O trabalho com estes sujeitos acontece na perspectiva de formação de um sujeito crítico por meio dos instrumentos pedagógicos. Eles norteiam o trabalho pedagógico, dentre outros objetivos, visam conhecer a realidade dos alunos e assim planejar e repensar formas de inclusão proporcionando condições para a realização das atividades mesmo que voltadas para o campo.

Diferentemente da migração histórica de estudantes do meio rural para a cidade, percebemos um caminho inverso de alunos urbanos que buscam uma 
nova experiência de vida na EFA. Muitas vezes, são alunos que estão desacreditados por escolas e até pelos pais. Chegam à escola e se percebem como centro do processo educativo, ou seja, como sujeito de sua aprendizagem. Dessa forma, passam a acreditar novamente em si mesmo. Notamos que a Pedagogia da Alternância faz a diferença na vida desses alunos, e o vínculo com a escola perpassa a conclusão dos estudos, pois retornam à unidade de ensino e a realização é nítida em muitas falas.

Frisamos ainda que o objetivo da Pedagogia da Alternância não é "fixar" o educando no campo. A instituição oferece possibilidades e condições para potencializar o caminho percorrido pelo aluno em relação ao conhecimento já que a Pedagogia da Alternância oferece uma formação integral e crítica do ser humano.

\section{Referências}

BEGNAMI, J. B. Pedagogia da Alternância como sistema educativo. Revista da Formação por Alternância. Brasília: UNEFAB, 2006, n. 3. p. 24-47.

CALDART, Roseli Salete. Por Uma Educação do Campo: traços de uma identidade em construção. In: KOLLING, Edgar Jorge; CERIOLI, Paulo Ricardo; CALDART, Roseli Salete (Orgs.). Educação do Campo: identidade e políticas públicas. Brasília, DF: Articulação Nacional Por Uma Educação do Campo, 2002.

DESLANDES, Suely Ferreira. Et al. A construção do projeto de pesquisa. In: DESLANDES, Suely Ferreira. Pesquisa Social: Teoria, método e criatividade. Petrópolis, RJ: Vozes, 2009. p.31-39.

DUFOUR, Dany- Robert. A arte de reduzir as cabeças: Sobre a nova servidão na sociedade ultraliberal. Rio de Janeiro: Companhia de Freud, 2005.

FREIRE, Paulo. Pedagogia da Autonomia: saberes necessários à prática educativa. 48. ed. São Paulo: Paz e Terra, 2014.

Terra, 1987.

. Pedagogia do oprimido. 17. ed. Rio de Janeiro: Paz e

GIMONET, Jean-Claude. Praticar e compreender a pedagogia da alternância dos CEFFAs. Tradução Thierry de Burghgrave. Petrópolis - RJ: Vozes, 2007.

LIBÂNEO, José Carlos. Pedagogia e pedagogos: inquietações e buscas. In: LIBÂNEO, José Carlos. Artigos de demanda continua. Curitiba: Educar, 2001. p. 153-176. 
MEPES - Movimento de Educação Promocional do Espírito Santo - EFTUR Nossa Escola Disponível em: <http://www.mepes.org.br/45-anos-efa-olivania> Acesso em: 26 mai. 2016.

\section{Sobre os autores}

\section{Samuel Pinheiro da Silva Santos}

samuelmemore@gmail.com

Possui graduação em História (Bacharelado e Licenciatura), Pós-Graduação em Educação de Jovens e Adultos e Mestrado em Ensino na Educação Básica pela Universidade Federal do Espírito Santo (2020). Atualmente é professor de História da Prefeitura Municipal de São Mateus/ES. Tem experiência na área de História e estudos na área de Educação das Relações Étnico-Raciais, Filosofia e Educação do Campo.

\section{Flaviane Geraldo}

flavianegeraldo@hotmail.com

Trabalha como monitora na Escola Família Agrícola de Olivância (MEPES). É graduada em História (licenciatura plena) pela Universidade Metropolitana de Santos (2017), com Pós-Graduação (Lato Sensu) em Educação Inclusiva e Diversidade pela Faculdade de Vitória (2017). Possui graduação em Educação do Campo, na área de Linguagens (licenciatura plena) pela Universidade Federal do Espírito Santo (2019). Tem experiência nas áreas de Lingua Portuguesa, Arte e Educação Física no Ensino Fundamental.

\section{Patricia Hand Littig}

patriciahl2005@hotmail.com

Possui graduação em História pela Universidade Metropolitana de Santos (2011), graduação em Pedagogia pela Universidade de Uberaba (2008) e graduação em Educação do Campo pela Universidade Federal do Espírito Santo (2019). Atualmente é professora de História na Escola Família Agrícola São Bento do Chapéu, Domingos Martins - ES e mestranda do programa de pósgraduação de mestrado profissional em educação do Centro de educação na Universidade Federal do Espírito Santo.

\section{Wellington Raach}

raaschwellington@gmail.com

Possui o curso Técnico em Agropecuária pela Escola Família Agrícola de Olivânia (2010) e Licenciatura Plena em Educação do Campo - Linguagens pela Universidade Federal do Espírito Santo (2019). Em 2020 atuou como professor de Artes na rede municipal de ensino de Domingos Martins/ES. 